\title{
Derecho humano a la verdad. El escrache como acto parrhesiástico
}

\author{
Antares Dadiuk ${ }^{1} \quad \mid$ Universidad Nacional \\ Carolina Julia Torres ${ }^{2}$ de La Plata
}

Revista Derechos en Acción ISSN 2525-1678/ e-ISSN 2525-1686

Año 4/Nº 11 Otoño 2019 (21 marzo a 21 junio), 513-540

DOl: https://doi.org/10.24215/25251678e289

\section{Introducción}

Escrache es una palabra proveniente del lunfardo -habla que originariamente empleaba, en la ciudad de Buenos Aires y sus alrededores, la gente de "clase baja"-, que según el diccionario de la Real Academia Española (RAE), significa: 1). Romper, destruir, aplastar (tr. coloq. Arg. y Ur). 2). Fotografiar a una persona (tr. coloq. Arg. y Ur. ).

\footnotetext{
Abogada, egresada de la UNLP en el año 2007. Tesis en curso de la Maestría en derechos humanos de la UNLP. Actualmente se desempeña como Auxiliar letrada de la Defensoría de Casación de la Provincia de Buenos Aires. Ha escrito diversos artículos relacionados con temas de derechos humanos y género. Asistente a Congresos sobre DDHH, Derecho Penal y sobre violencia de Género. Ha participado en capacitaciones y conversatorios sobre Derechos Humanos y en el seminario de grado sobre Derecho a la Educación, Educación en DDHH y Género de la FCJS de la UNLP, como expositora. Su historia laboral ha sido vinculada al campo de los derechos humanos en el Poder ejecutivo y en el legislativo.

2 Abogada, egresada de la UNLP en el año 1996. Tesis en curso de la Maestría en Derechos Humanos de la UNLP. Actualmente se desempeña como Instructora Judicial en laFiscalía (UFIJ) N ${ }^{0} 17$ de La Plata, cargo de abogada adscripta de la SCJBA. Ha realizado cursos de Instructora judicial, de Ayudante Fiscal, de Especialización en Derecho Penal de la UBA, de la Escuela Judicial del Consejo de la Magistratura, en Género y Movimientos Feministas. Asistente a Congresos sobre DDHH, Derecho Penal y sobre violencia de Género. Colaboradora en distintos organismos de DDHH, participación en capacitaciones y conversatorios sobre Derechos Humanos y en el seminario de grado sobre Derecho a la Educación, Educación en DDHH y Género de la FCJS de la UNLP, como expositora. Su trayectoria laboral está ligada al asesoramiento jurídico a movimientos sociales, y como instructora judicial en distintas Fiscalías de la Plata.
} 
También deriva del genovés scraccá que apunta a la acción de expectorar o agredir a alguien de lo cual se seguiría el sentido que "escrachar" adopta en varias letras de tangos.

Los escraches como nueva forma de protesta irrumpieron en la escena social de Argentina en la década de los años 90, década en que también aparece la agrupación HIJOS $^{3}$ como nuevo actor social.

Los escraches constituyeron protestas sociales que se generaron como respuesta al Estado ante la impunidad de los crímenes cometidos durante la última dictadura cívico-militar en Argentina. Las protestas se realizaban en los domicilios particulares o laborales de los genocidas. Con estos actos se pretendía una "condena social" ya que no existía condena legal por parte del Estado. Se buscaba visibilizar los victimarios. "La condena social" no era solamente el día del escrache, comenzaba días antes "marcando la casa", se hablaba con los vecinos y continuaba días después del escrache, cuando tomaba estado público que allí vivía un genocida, y se visibilizaba para toda la sociedad.

Más allá de las múltiples visiones desde donde se puede analizar esta nueva forma de acción colectiva ${ }^{4}$, a nosotras nos interesa el análisis de su visión como acto veraz, (o verídico). Vemos al escrache como forma de protesta social, ejercida por toda la sociedad como víctima del terrorismo de Estado instalado por el autodenominado "proceso de reorganización

3 La sigla significa: hijos por la identidad y la justicia contra el olvido y el silencio. Esta agrupación está conformada centralmente por hijos de víctimas del terrorismo de Estado.

4 Al respecto, Maristella Svampa en su libro La sociedad excluyente, señala: "La consolidación de nuevas pautas de inclusión y exclusión social, en el marco de la puesta en marcha de políticas neoliberales, tuvo una repercusión importante en el plano de la acción colectiva. Así en América latina durante los años 80 y la primera mitad de los 90, en contraste con el proceso de concentración creciente de la decisiones en las elites de poder internacionalizado, los sistemas de acción colectiva pasaron por un momento de inflexión -de crisis y debilitamiento-, visible en la fragmentación de las luchas, la focalización en demandas puntuales, la presión local o la acción espontánea y semiorganizada (Calderón y Dos Santos, 1995)" (Svampa, 2005: 199) 
nacional" ${ }^{5}$, como la petición de su derecho fundamental a conocer la verdad y luchar por ella, más allá del riesgo y el peligro que este ejercicio implicara.

En este sentido, partimos desde el concepto de derechos humanos elaborado por Herrera Flores:

Los Derechos humanos en su integralidad (derechos humanos) y en su inmanencia (trama de relaciones) pueden definirse como el conjunto de procesos sociales, económicos, normativos, políticos y culturales que abren y consolidan -desde el "reconocimiento" y la "transformación de poder" y la "mediación jurídica" - espacios de lucha por la particular concepción de la dignidad humana. (Herrera Flores, 2000: 27)

Entendemos este concepto de derechos humanos en virtud del proceso social de lucha de los organismos de derechos humanos, en contra de la impunidad de las leyes del perdón ${ }^{6}$. En el proceso de lucha es justamente donde se enmarcan los escraches como nueva forma de protesta y de ejercicio del derecho fundamental a la verdad. Este es un derecho humano ya reconocido por la jurisprudencia argentina como "el derecho al reconocimiento de aquellas víctimas y toda la sociedad, de graves violaciones a los derechos humanos, como los familiares de personas desaparecidas a conocer la verdad acerca de las circunstancias de su desaparición y a obligar al Estados a buscar sus cuerpos (Fallos de la Corte Suprema de Justicia: 1998).

Asimismo, el derecho a la verdad se consagra en la Jurisprudencia de la Corte Interamericana de derechos humanos en

5 Dictadura instalada en Argentina el 24 de marzo de 1976, y que permaneció hasta diciembre de 1983. Raúl Alfonsín, elegido por el voto popular, asumió el 10 de diciembre de 1983.

6 Se llamó de este modo a las leyes de Obediencia debida y Punto final: En 1987 comenzaron las actuaciones judiciales contra oficiales del Cuerpo I de Ejército y de la Escuela de Mecánica de la Armada (ESMA). Se produjeron entonces los alzamientos de los militares carapintada (por la pintura de camuflaje que utilizaban los comandos del ejército). Bajo esa presión, el gobierno de Alfonsín consiguió que el Congreso votara la Ley de Obediencia Debida. Hubo todavía nuevos alzamientos militares porque a pesar de ella seguían todavía bajo proceso un par de centenares de oficiales de las Fuerzas Armadas. (Verbitsky, 2011: 36) 
los siguientes casos: "Panel Blanca" (Paniagua Morales y otros vs. Guatemala Sentencia de 8 de marzo de 1998), "Niños de la Calle" (Villagrán Morales y otros vs. Guatemala. Sentencia de 19 de noviembre de 1999), "Velázquez Rodríguez vs. Honduras", Sentencia de 26 de junio de 1987, entre otros. Y, luego, expresamente en la Convención Internacional para la protección de todas las personas contra las desapariciones forzadas, que en su preámbulo refiere "Afirmando el derecho a conocer la verdad sobre las circunstancias de una desaparición forzada y la suerte de la persona desaparecida, así como el respeto del Derecho a la libertad de buscar, recibir y difundir informaciones a este fin" (Asamblea General de las Naciones Unidas. Aprobado el 20 de diciembre de 2006).

\section{Etimología de "escrachar"}

Esta palabra proviene del habla o dialecto usado en sus orígenes por las clases populares de la ciudad de Buenos Aires y otras localidades rioplatenses, conocida como "lunfardo". Parte de sus vocablos y locuciones se introdujeron posteriormente en la lengua popular y se difundieron en el español de Argentina y Uruguay. Nos interesa resaltar la importancia de su origen y su etimología, porque su elección no es casual, muy por el contrario, su origen nos remite a su significado, su identidad y pertenencia con nuestra sociedad.

El escritor y periodista argentino Roberto Arlt, en alusión a las críticas literarias de escritores de la época al lunfardo en pos de la academia y las gramáticas, dijo "que considera que los pueblos como el nuestro que están en continua evolución inventan palabras para expresar ideas nuevas y cambiantes". (Arlt: 222)

El significado de "fotografiar", naturalmente derivado de "escracho" o "escrachador: fotógrafo" y "escrachería: taller fotográfico", no es el que más nos interesa, porque, aunque alguna vez pudo tener cierta utilización, especialmente literaria. 
La acepción que elegimos, y con la que se emplea popularmente desde hace más de un siglo, es la que apareció en el diario Crítica del 24 de noviembre de 1913 en el Novísimo Diccionario Lunfardo, que se publicó durante un par de años y que firmaba, con nombre de fantasía, Ruben Fastrás, como: "romperle la cara a castañazos a una persona; irla de contundencia hasta el punto de dejarlo desconocido a una grela o a un bacán también." Y cita como ejemplo: "Y la tuve que escrachar / Para hacer que se callara" (Gobello y Stilman, 1964: 105). La frase citada nos demuestra que la voz ya era conocida para esa época con la idea de "golpe".

Encontramos en el Diccionario Le Robert cracher: Projeter de la salive, des mucosités de la bouche (V. intr. 1). ${ }^{7}$

La acepción deriva del genovés scraccá que apunta a la acción de expectorar o agredir a alguien de lo cual se seguiría el sentido que "escrachar" adopta en varias letras de tango. En ese sentido, la encontramos en la lectura de los tangos, o el sainete, expresiones culturales que fueron forjando una identidad cultural propia, rioplatense. ${ }^{8}$

\section{El escrache como nueva forma de protesta}

\section{Contexto social. Crisis de la década de 1990 en Argentina}

La década de 1990 se presenta con la instauración, en Argentina, de un modelo neoliberal y, en el contexto internacional, ${ }^{9}$ de una crisis caracterizada por el fin de las ideologías y una apatía generalizada.

\footnotetext{
7 Dictionnaires Le Robert. 2006.

8 En los siguientes tangos: "Viva el Tango" de Ferrer y Garello, "Pinta Brava", letra de Mario Batistella; "El Chamuyo" letra de Yacare y música de Edmundo Rivero; "La Señora de Chalet" letra de José Pagano y música de Edmundo Romero. Y "la milonga dirá", poema lunfardo de José María Otero.

9 Se toma como fecha la caída del Muro de Berlín en 1989, que durante 28 años dividió a Berlín Occidental de la República Democrática Alemana (RDA). Su eliminación significó el fin del régimen de la RDA y de los regímenes comunistas en Europa Oriental.
} 
En la Argentina, como en toda la región, este escenario tuvo su repercusión: una crisis en las formas de protesta social, de acción colectiva.

Esta crisis se vio a su vez nutrida en las distintas organizaciones o movimientos sociales por varias medidas del sector político, así como de los órganos que las dirigían por sus alianzas al gobierno neoliberal del momento.

En el caso de las organizaciones de derechos humanos, su accionar y su lucha se vieron replegados por el duro golpe sufrido por las amnistías e indultos ${ }^{10}$ otorgados a algunos responsables de la última dictadura cívico-militar, que habían sido condenados en el juicio a las Juntas en causa $13^{11}$.

De este modo, los diferentes actores sociales, verían replegadas sus formas de acción y de protesta ante el avance de un modelo neoliberal que se presentaría como único e incuestionable. Se impuso desde el discurso, la idea del Estado corrupto, mal administrador y un monstruo incontrolable al que inevitablemente había que quitarle participación e intervención y limitarlo a ser sólo un órgano de gestión, devolviéndole al mercado la regulación libre de la oferta y demanda de servicios. A ello, siguió la implementación del proceso privatizador de las empresas estatales, de los recursos naturales, y se llegó incluso

\footnotetext{
10 La Ley de Punto Final extinguía la acción penal respecto de toda persona por su presunta participación en Is crímenes cometidos durante la dictadura. La Ley 23.521 establecía que, quienes revistaban-como oficiales, jefes, oficiales subalternos, suboficiales y personal de tropa de las Fuerzas Armadas, de seguridad, policiales y penitenciarias- no eran responsables de los hechos punibles referidos en el art 10, unto uno, de la Ley 23.049 por haber obrado en virtud de obediencia debida. Con el cambio de gobierno en la República Argentina, el nuevo presidente, Carlos Saúl Menen, a finales de 1989 y a principios de 1990, dictó diferentes decretos de indultos que supusieron el final de todas las causas penales que estaban tratándose en aquel momento.

11 El Juicio a las Juntas (conocido también como Causa 13) fue el proceso judicial Ilevado a cabo por la justicia civil (por oposición a la justicia militar) en la Argentina en 1985, por orden del presidente Raúl Ricardo Alfonsín (1983-1989) contra las tres primeras juntas militares de la dictadura (1976-1983) debido a las graves y masivas violaciones de derechos humanos cometidas en ese período. La sentencia condenó a algunos integrantes de las tres primeras juntas militares a severas penas.
} 
a traspasar a empresas privadas los fondos jubilatorios. Lo anterior fue acompañado con un proceso de ajuste del gasto público, de políticas de flexibilización laboral y de criminalización de la protesta social, pero con una "economía estable", en paridad con el dólar. La economía era la piedra angular salvadora de las realidades que se presentaban y, por el contrario, las ideologías, (la participación activa, la militancia social) eran consideradas de una época ya pasada.

La situación regional e internacional contribuía a estas ideas, junto con el derrocamiento del bloque socialista soviético y la concentración de un solo poder central, en el cual Estados Unidos era el actor principal.

La situación sociopolítica general conllevó al descreimiento, la apatía política, ante un futuro que se presentaba como predeterminado, con imposibilidad de cambios profundos.

\section{Nuevas formas de protesta}

Estas crisis en las formas de acción colectivas conocidas y aprendidas hasta ese momento, las derrotas sufridas en el campo popular, originaron en la Argentina así como en el resto de la región y en el mundo nuevas formas de protesta social ${ }^{12}$, nuevos actores sociales y distintas formas de participación y de resistencia a las políticas neoliberales estatales, en oposición a lo que pregonaban los portavoces del poder instalado, las ideologías dominantes e intelectuales de la época. En este sentido, seguimos a Javier Auyero, cuando expresa:

La forma de la protesta tiene que ver con procesos políticos y con formas de reclamo aprendidas en repetidos enfrentamientos con el Estado y con su relativo éxito

\footnotetext{
12 "A partir del 2001 el uso de la "categoría de protesta social" desbordó el campo académico para pasar a constituir una suerte de concepto común, periodístico y político. En este sentido, es necesario aclarar que la noción de protesta aparece definida en el marco del paradigma de la interacción estratégica en función de dos rasgos mayores: el carácter contencioso de la acción y su visibilidad pública." (Svampa, 2005: 318).
} 
o fracaso. Las maneras en que la gente formula sus reclamos tiene que ver entonces con la política y con la cultura de la acción colectiva. (Auyero, 2002: 14)

Auyero retoma a Tilly, en cuanto ha estudiado la relación entre cambio social de gran escala y el carácter de la acción colectiva, y expresa:

Las instituciones democráticas duraderas surgen de luchas repetidas de largo plazo, en las que trabajadores, campesinos y otra gente común han estado involucrados (...) las revoluciones, rebeliones, y movilizaciones de masas marcan una diferencia significativa entre un país $\mathrm{y}$ otro con respecto al alcance de la democracia. (AUYERO. 2002: 15)

En Argentina se presentan nuevos repertorios, que irrumpen en el escenario social como formas de protesta, de acción colectiva, un cúmulo de rutinas aprehendidas y compartidas mediante las cuales los diferentes grupos sociales formulan sus reclamos. Dentro de estas nuevas formas de protesta social encontramos los movimientos de matriz sindical, organizaciones relacionadas con la defensa de los derechos cívicos, movimientos de matriz territorial ligados a nuevas formas de autoorganización barrial o a la lucha por la tierra y la defensa del hábitat, las organizaciones piqueteras ${ }^{13}$ y de desocupados y también organizaciones de derechos humanos. En este contexto, aparece un nuevo actor: la agrupación HIJOS.

\section{El escrache}

Es en la situación social de Argentina que venimos describiendo donde emergen los escraches como nueva forma de protesta social, de acción colectiva, pero también como "decir

\footnotetext{
13 Título que no derivó de su condición social (desempleados) o de sus demandas, sino de su acción misma [...] Así fueron llamados y ese nombre asumieron para sí. Fueron lo que hicieron. Su identidad social (desempleados) se transformó por fuerza de su identidad política (piqueteros) (Schuster, F., 2005, p. 52).
} 
veraz", como acto verídico en contraposición a la negación de la verdad por parte de los órganos judiciales encargados de su investigación, y la agrupación HIJOS. como nuevo "ethos" militante.

Luego de los indultos, se produce un fuerte impacto en el seno de las organizaciones de derechos humanos, lo que provoca el desplazamiento hacia la búsqueda de una condena social y hacia la reconstrucción de la memoria colectiva acerca del significado y las consecuencias del terrorismo de Estado. La falta de condena judicial acentuó la necesidad de profundizar la disputa en el terreno cultural. En este contexto, en Argentina, con la agrupación HIJOS aparecen los escraches como acción directa de modo tal que se puede afirmar que HIJOS fue quien instaló esta práctica. Claramente, la necesidad de esta agrupación pasaba, en ese entonces, por denunciar la impunidad institucional: la votación del Poder Legislativo de las leyes de Obediencia Debida y Punto Final y los decretos presidenciales del indulto.

En diciembre de 1996, se produjo el primer escrache: un grupo de aproximadamente treinta y cinco personas apareció en un sanatorio privado de la ciudad de Buenos Aires para denunciar que allí trabajaba un médico involucrado en violaciones a los derechos humanos (Jorge Luis Magnacco) acusado de presenciar sesiones de tortura, asistir a mujeres en sus partos en un centro clandestino de detención y denunciado por apropiaciones de bebés.

Más adelante, se definiría el repudio a Magnacco como "el primer escrache". Es importante destacar que la identificación de este repudio como un escrache fue una resignificación posterior, ya que en ese momento ni los propios integrantes de HIJOS ni los medios de comunicación lo definieron de ese modo.

Podemos decir, entonces, que el escrache argentino fue "inventado" por HIJOS. Eso contribuyó a la revitalización de la lucha por los derechos humanos en esa adversa situación, 
al evidenciar públicamente la impunidad de los genocidas y al apuntar a generar una condena social ante la ausencia de cualquier tipo de condena legal.

En el recorrido histórico que nos hemos propuesto con relación a los escraches advertimos algunos aportes de ONG vinculadas con el arte y la política o, como algunos denominan, "arte activista".

El grupo Etcétera aportó a los escraches sus performances con estilo "grotesco": con grandes muñecos, máscaras o disfraces. Representaba en la puerta de la vivienda o del lugar de trabajo del exgenocida, en medio de la movilización con la que concluía cada escrache, escenas de tortura, genocidas en el acto de apropiarse de un bebé, hijo de una prisionera o un militar limpiando sus culpas al confesarse con un cura.

Tanto los carteles del $\mathrm{GAC}^{14}$ como las creaciones artísticas de Etcétera proporcionaron una indiscutible identidad y visibilidad social a los escraches, y contribuyeron a que se evidenciaran como una nueva y contundente forma de protesta contra la impunidad instalada en ese entonces.

A diferencia de las rondas que todos los jueves realizan las Madres $^{15}$ en torno a la pirámide de la Plaza de Mayo, los escraches constituían una práctica dispersa; podían ocurrir de improviso en cualquier parte del país: "A dónde vayan los

\footnotetext{
14 Es Grupo de Arte Callejero, por eso su nombre. Desde su formación en 1997, el GAC realizó trabajos en conjunto con diversas agrupaciones como la Mesa de Escrache Popular, HIJOS, Madres de Plaza de Mayo línea fundadora, Serpaj (Servicio de Paz y Justicia), diferentes colectivos de arte y organismos de derechos humanos, CORREPI (Coordinadora contra la Represión Policial e Institucional), familiares de los asesinados el 20 de diciembre, varios MTD (Movimiento de Trabajadores Desocupados), delegados de Metrovías, Argentina arde, Cine Ambulante, entre muchos más.

15 Todos los jueves, desde el año 1977, las madres de personas desaparecidas durante la última dictadura realizan una caminata silenciosa pidiendo la aparición de sus hijos/as en torno a la pirámide de la Plaza de Mayo, punto nodal de la ciudad alrededor del que se concentran los edificios que condensan el poder simbólico, político, religioso y económico de la nación.
} 
iremos a buscar"16, se coreaba en las protestas. Al mismo tiempo, si las estrategias simbólicas de las Madres de Plaza de Mayo habían apuntado a dar visibilidad a las víctimas de la dictadura, HIJOS buscaba evidenciar la existencia de victimarios, intentaba expandir la condena social ante la evidente impunidad ("Si no hay justicia, hay escrache" era la consigna).

Las características y las formas de organizar los escraches fueron variando con el tiempo, pero la estructura básica de la protesta tendía a repetirse. Una vez que HIJOS decidía el nombre de la persona que iban a escrachar, buscaba y corroboraba sus datos básicos. Luego mandaba a imprimir volantes y afiches con toda esa información y la convocatoria para el día del escrache. Ese material era distribuido fundamentalmente en el barrio y en distintos lugares de la ciudad, como por ejemplo en aquellos colegios y facultades más comprometidos con los derechos humanos Llegado el día, todas las personas convocadas se encontraban en un lugar cercano, desplegaban sus banderas y cuando reunían una cierta cantidad de personas marchaban todas juntas por las calles del barrio, entonando canciones contra el genocida o las fuerzas de seguridad. Cuando llegaban a la casa del acusado, realizaban una parodia o representación teatral, leían un breve discurso y luego marcaban el domicilio con pintura. La cantidad de manifestantes era muy variable y podía oscilar entre trescientas y dos mil personas, según el escrache. La gran mayoría de los concurrentes era joven, a excepción de unos pocos antiguos "militantes"17. Por la población movilizada tanto como por la forma de organizarlos y por los recursos utilizados, los escraches tenían una clara impronta generacional, pues eran un producto típicamente juvenil.

Los escraches consiguieron explotar y desarrollar mucho más la potencialidad que tenía el movimiento de derechos

\footnotetext{
16 Cántico que instalaron desde siempre los organismos de derechos humanos en Argentina, en todas las marchas y luego escraches, cuando de genocidas se hablaba.

17 Palabra utilizada en argentina para hacer referencia a aquellas personas defensoras de una ideología o pertenecientes a un grupo, movimiento social o partido político.
} 
humanos en la Argentina (que había recurrido tradicionalmente a la utilización de fotografías o de imágenes como forma de expresar sentimientos que difícilmente se podían expresar en palabras). En ese sentido, una práctica frecuente durante las marchas era la reapropiación de símbolos o elementos que formaban parte del paisaje urbano y resignificarlos con un contenido vinculado al escrache. Por ejemplo, a medida que los manifestantes se acercaban al domicilio del genocida aprovechaban para colgar carteles que imitaban el formato y la estética de las señales de tránsito oficiales, pero con dibujos o leyendas alusivas que advertían "Cuidado: a $300 \mathrm{~m}$ asesino suelto", con el nombre y dirección de la persona escrachada.

Una cuestión para destacar es que el escrache terminaba convirtiéndose en un "evento festivo". Había murgas ${ }^{18}$, personas disfrazadas y muñecos construidos especialmente para ese evento que representaban al genocida. Durante los escraches, también se realizaban pequeñas obras teatrales, en las que se satirizaba a la persona del genocida o a las fuerzas de seguridad. Este clima que venimos describiendo no era casual, sino promovido por los organizadores de la protesta, que buscaban de ese modo alejar el fantasma del dolor y la tristeza. Desde su formación HIJOS cuestionó la recuperación que se hacía de los desaparecidos únicamente desde el lugar del sufrimiento y del dolor. Aun sin dejar de admitir que sus historias tenían un componente ineludible de dolor, desgarros y ausencias, HIJOS no quería que esos elementos se convirtieran en el rasgo distintivo de sus prácticas.

Los escraches empezaron a formalizarse con mayor planificación y regularidad en 1998. Es allí cuando tienen el mayor impacto sobre la sociedad, porque consiguen una amplia repercusión pública. Fue ese año cuando los principales diarios y revistas del país comenzaron a publicar notas y editoriales

\footnotetext{
18 Género artístico rioplatense que combina música y teatro. Dicha denominación también se aplica a las agrupaciones que también desarrollan este tipo de manifestación artística, que es muy frecuente en tiempos de carnaval y en otras festividades.
} 
sobre "el escrache". Inclusive, los informativos les dedicaron mayor importancia y también llegaron a transmitirlos en vivo. La popularidad de los escraches fue más allá de las fronteras argentinas, la propia modalidad del escrache comenzó a ser utilizada por el movimiento de derechos humanos de países vecinos como Uruguay y Chile. Incluso periodistas extranjeros se interesaron en realizar notas y documentales sobre el tema.

Los escraches fueron modificándose con el paso del tiempo, según el contexto político y las necesidades o intereses de la agrupación. El primer objetivo que tuvo el escrache fue dar a conocer cuáles eran los rostros de los genocidas, dejarlos expuestos públicamente frente a sus vecinos, ya que, si bien habían tenido una participación directa en la dictadura, no eran conocidos por toda la sociedad.

El trabajo en el barrio que realizaban los "escrachadores", no terminaba en el hecho de "marcar la casa". Se preparaban días previos al escrache, cuando "los militantes" iban a hablar con los vecinos, les contaban quién era el genocida que vivía en ese lugar, su historia, etc. Luego realizaban "la marca de la casa del genocida". Pero el escrache no terminaba allí, ya que al día siguiente el escrache continuaba, porque como dicen ellos "el panadero no les vende el pan, el diariero le niega el diario y el vecino no lo saluda. Ese es el verdadero escrache". (Bonaldi, 2006:24)

En un primer momento, entonces, los escraches estuvieron a cargo de HIJOS, pero inmediatamente, agrupaciones, colectivos de arte y otras personas individualmente comenzaron a unirse para colaborar en esta nueva idea de protesta social.

\section{Derecho Humano a la verdad}

Resulta interesante destacar el análisis que se realiza en el libro GAC acerca de la memoria:

Una memoria de alguna manera es una visión del mundo social e histórico, por ese motivo no existe "la memoria", 
sino las memorias, las visiones, las selecciones, los olvidos, los recuerdos optados al paso del tiempo y las construcciones colectivas de esos hechos pasados. Por esta complejidad, las memorias no son meros recuerdos, sino construcciones de individuo-sociedad en relación dinámica y conjunta enmarcadas en un momento histórico-social. Las memorias evocan disputas de sentido, valor, poder, etc.: abandonando la falsa idea de una "memoria completa". (GAC, 2009: 55)

Las memorias son múltiples como los distintos sujetos que integran la sociedad misma. Según Michel Foucault, no existen relaciones de poder sin resistencias; la resistencia existe porque está allí donde el poder está: es pues, como él, múltiple e integrable. Desde la Mesa de Escrache, construir resistencias es una respuesta en oposición a la trascendencia de las organizaciones sociales, es decir "basta". Con el proceso del escrache se intenta un camino de poder como verbo, del poder-hacer como poder relacionarse, poder reconocerse en las diferencias y similitudes, poder construir colectivamente. "En este proceso de construir colectivamente la memoria no es un rompe- cabezas donde sus piezas forman una única imagen, [...] sino que hay que sumar las voces para ir armando, en lugar de un puzzle en que cada pieza tiene un solo lugar, una especie de caleidoscopio que reconoce distintas figuras posibles" (Calveiro. 2005: 19). Se crean de este modo prácticas políticas mediante la alegría, lo festivo y la reflexión.

Michel Foucault afirma que la verdad no queda ajena a la cuestión del poder: la verdad se produce a partir de múltiples relaciones y luchas por el poder, disputas, agonísticas constantes que conllevan efectos en los individuos, en las instituciones, y por supuesto en el amplio dominio del saber. Cada sociedad construye su régimen de verdad, su "política general de la verdad"; lo que equivale a decir que cada sociedad produce históricamente los rituales y mecanismos que permiten aceptar lo verdadero y rechazar lo falso. La verdad, por lo tanto, no se encuentra fuera del poder ni carece de 
efectos de poder. De esta manera, el planteamiento de la verdad conduce a la política.

La verdad, como derecho humano fundamental, también ha tenido desarrollo en el sistema interamericano y en el derecho interno.

La jurisprudencia de la Corte Interamericana y la Comisión Interamericana, tiene un amplio desarrollo del concepto y alcance del Derecho a la Verdad. Inicialmente, la Comisión consideró que se trata del derecho de las familias a conocer la qué sucedió con sus seres queridos, derivado de la obligación que tienen los Estados de brindar a las víctimas o sus familiares un recurso sencillo y rápido que los amparara contra violaciones de sus derechos fundamentales, conforme al Artículo 25 de la Convención Americana sobre derechos humanos:

Art. 25: 1. Toda persona tiene derecho a un recurso sencillo y rápido o a cualquier otro recurso efectivo ante los jueces o tribunales competentes, que la ampare contra actos que violen sus derechos fundamentales reconocidos por la Constitución, la ley o la presente Convención, aun cuando tal violación sea cometida por personas que actúen en ejercicio de sus funciones oficiales.

2. Los Estados Partes se comprometen: a) a garantizar que la autoridad competente prevista por el sistema legal del Estado decidirá sobre los derechos de toda persona que interponga tal recurso; b) a desarrollar las posibilidades de recurso judicial, y c) a garantizar el cumplimiento, por las autoridades competentes, de toda decisión en que se haya estimado procedente el recurso."

La interpretación de este derecho ha evolucionado. Actualmente es considerado como un derecho que pertenece a las víctimas y sus familiares y también a la sociedad en general. Conforme a esta concepción, el derecho a la verdad se basa no sólo en el Artículo 25, sino también en los artículos 1(1), 8 y 13 de la Convención: 
Art. 1: 1. Los Estados Partes en esta Convención se comprometen a respetar los derechos y libertades reconocidos en ella y a garantizar su libre y pleno ejercicio a toda persona que esté sujeta a su jurisdicción, sin discriminación alguna por motivos de raza, color, sexo, idioma, religión, opiniones políticas o de cualquier otra índole, origen nacional o social, posición económica, nacimiento o cualquier otra condición social.

Art. 8: 1. Toda persona tiene derecho a ser oída, con las debidas garantías y dentro de un plazo razonable, por un juez o tribunal competente, independiente $\mathrm{e}$ imparcial, establecido con anterioridad por la ley, en la sustanciación de cualquier acusación penal formulada contra ella, o para la determinación de sus derechos y obligaciones de orden civil, laboral, fiscal o de cualquier otro carácter.

2. Toda persona inculpada de delito tiene derecho a que se presuma su inocencia mientras no se establezca legalmente su culpabilidad. Durante el proceso, toda persona tiene derecho, en plena igualdad, a las siguientes garantías mínimas: a) derecho del inculpado de ser asistido gratuitamente por el traductor o intérprete, si no comprende o no habla el idioma del juzgado o tribunal; b) comunicación previa y detallada al inculpado de la acusación formulada; c) concesión al inculpado del tiempo y de los medios adecuados para la preparación de su defensa; d) derecho del inculpado de defenderse personalmente o de ser asistido por un defensor de su elección y de comunicarse libre y privadamente con su defensor; e) derecho irrenunciable de ser asistido por un defensor proporcionado por el Estado, remunerado o no según la legislación interna, si el inculpado no se defendiere por sí mismo ni nombrare defensor dentro del plazo establecido por la ley; f) derecho de la defensa de interrogar a los testigos presentes en el tribunal y de obtener la comparecencia, como testigos o peritos, de otras personas que puedan arrojar luz sobre los hechos; g) derecho a no ser obligado a declarar contra sí 
mismo ni a declararse culpable, y h) derecho de recurrir del fallo ante juez o tribunal superior.

3. La confesión del inculpado solamente es válida si es hecha sin coacción de ninguna naturaleza.

4. El inculpado absuelto por una sentencia firme no podrá ser sometido a nuevo juicio por los mismos hechos.

5. El proceso penal debe ser público, salvo en lo que sea necesario para preservar los intereses de la justicia" Art. 13: 1. Toda persona tiene derecho a la libertad de pensamiento y de expresión. Este derecho comprende la libertad de buscar, recibir y difundir informaciones e ideas de toda índole, sin consideración de fronteras, ya sea oralmente, por escrito o en forma impresa o artística, o por cualquier otro procedimiento de su elección.

2. El ejercicio del derecho previsto en el inciso precedente no puede estar sujeto a previa censura sino a responsabilidades ulteriores, las que deben estar expresamente fijadas por la ley y ser necesarias para asegurar: a) el respeto a los derechos o a la reputación de los demás, o b) la protección de la seguridad nacional, el orden público o la salud o la moral públicas.

3 . No se puede restringir el derecho de expresión por vías o medios indirectos, tales como el abuso de controles oficiales o particulares de papel para periódicos, de frecuencias radioeléctricas, o de enseres y aparatos usados en la difusión de información o por cualesquiera otros medios encaminados a impedir la comunicación y la circulación de ideas y opiniones.

4. Los espectáculos públicos pueden ser sometidos por la ley a censura previa con el exclusivo objeto de regular el acceso a ellos para la protección moral de la infancia y la adolescencia, sin perjuicio de lo establecido en el inciso 2 .

5. Estará prohibida por la ley toda propaganda en favor de la guerra y toda apología del odio nacional, racial o religioso que constituyan incitaciones a la violencia o cualquier otra acción ilegal similar contra cualquier 
persona o grupo de personas, por ningún motivo, inclusive los de raza, color, religión, idioma u origen nacional”.

En ese sentido, la Comisión manifestó que cuando se dictan amnistías, los Estados deben adoptar las medidas necesarias para establecer los hechos e identificar a los responsables. La Comisión también señaló que "toda sociedad tiene el derecho inalienable de conocer la verdad de lo ocurrido, así como las razones y circunstancias en las que aberrantes delitos llegaron a cometerse, a fin de evitar que esos hechos vuelvan a ocurrir en el futuro". ${ }^{19}$

La Comisión comprobó una violación del Artículo 13 respecto del derecho a la verdad en un caso en 1999, en El Salvador. En él, al constatar que se había violado el derecho a la verdad, señaló que el Estado tiene el deber de brindar a los familiares de las víctimas y a la sociedad en general información acerca de las circunstancias que rodearon las violaciones graves de los derechos humanos y acerca de la identidad de sus perpetradores, y afirma asimismo, que este derecho emana de los artículos 1(1), 8(1), 25 y 13. Por primera vez en este tipo de casos, la Comisión manifestó expresamente que el Estado había violado el artículo 13, señalando que la Convención Americana protege el derecho a acceder y a recibir información en su artículo 13. La cuestión del derecho a la verdad se suscitó ulteriormente en otros casos considerados por la Corte Interamericana de derechos humanos.

En el Caso de "Los niños de la Calle"20en el párrafo 204, la Comisión consideró al aludir a la violación del artículo 1.1, que "como resultado de las fallas del procedimiento judicial interno, a las familias de las víctimas se les negó su derecho a conocer y comprender la verdad y los derechos que trataban de reivindicar a través de los tribunales". También, y en el mismo lineamiento,

\footnotetext{
19 Informe Anual-2002 de la Relatoría Especial para la libertad de Expresión, párrafos 41 y 42.

20 Caso de los "Niños de la Calle" (Villagrán Morales y otros) Vs. Guatemala. CIDH.
} 
en el Caso Paniagua Morales ${ }^{21}$, párrafo 200, expresa que este Tribunal ha abundado en reiteradas ocasiones el derecho que asiste a los familiares de las víctimas de conocer qué sucedió, y de saber quiénes fueron los agentes del Estado responsables de tales hechos. Como ha señalado esta Corte, "la investigación de los hechos y la sanción de las personas responsables [...] es una obligación que corresponde al Estado siempre que haya ocurrido una violación de los derechos humanos y esa obligación debe ser cumplida seriamente y no como una mera formalidad".

Luego de analizar brevemente el derecho a la verdad en el contexto internacional, nos interesa detenernos en el derecho a la verdad exigido por la sociedad civil a través de los "juicios por la verdad" y del "escrache".

La característica distintiva de los denominados juicios por la verdad histórica radica en que no podían condenar penalmente a los responsables del genocidio en nuestro país. El proceso judicial tenía como único objetivo hallar el destino de los desaparecidos, recuperar los cuerpos y la verdad histórica. Vale aclarar que por aquellos años tenían plena vigencia "las leyes de impunidad".

En 1998 se da uno de los primeros pasos en aras de reactivar las causas paralizadas: se trata la primera causa que llega a la Comisión Interamericana de derechos humanos (CIDH) caratulada "AGUIAR DE LAPACO c/ Estado Argentino- Solución Amistosa". Es utilizando esta causa que la $\mathrm{CIDH}$ pronuncia el fallo que obliga al Estado Argentino a reabrir las causas con el único objeto de determinar cuál fue la verdad histórica y el destino final de los desaparecidos. Este fallo permitió trabajar con estos fines a muchas Cámaras Federales del país, a sabiendas de que no se condenaría a ningún militar, ya que sólo se buscaba el destino de los desaparecidos.

En el 2003 el Congreso de la Nación sancionó la Ley $\mathrm{N}^{\mathrm{o}}$ 25.779, que anula las Leyes de Punto Final y Obediencia

21 Caso de la "Panel Blanca" (Paniagua Morales y otros) Vs. Guatemala. CIDH. 
Debida. El 14 de junio del 2005 la Corte Suprema de Justicia de la Nación en un histórico fallo declara la inconstitucionalidad de la ley $23.492^{22}$ y de la Ley $23.521^{23}$ y a su vez declara la validez de la ley 25.779 (sancionada en el Congreso en 2003) que las anula.

\section{Derecho a la verdad. El escrache como acto verídico}

Analizaremos los escraches como nueva forma de protesta social fundamentada en el Derecho a la verdad, para relacionarlo con el concepto de parrhesía de Foucault.

Desarrollaremos el análisis del escrache a partir de las clases del 12 de enero de 1983 que dictó Michel Foucault en el College de France y que se receptan en su libro El gobierno de sí $y$ de los otros, como mecanismo de acción, de decir verdad, de hablar franco, de escupir la verdad ante un Estado que pretende ocultarla e ignorarla.

Foucault conceptualiza la parrhesía, palabra griega, como "decirlo todo", pero más ajustado, dice, "hablar franco". Es una virtud, un deber, una técnica, un procedimiento. En ese sentido expresa:

Esta noción de parrhesía, que era importante en las prácticas de la dirección de conciencia, [...] era una noción rica, ambigua, difícil en cuanto designaba en particular una virtud, una cualidad (hay gente que tiene la parrhesía y otra que no la tiene); también es un deber (es preciso, sobre todo en una serie de casos y situaciones, dar muestras concretas de parrhesía); y para terminar es una técnica un procedimiento: hay personas que saben valerse de la parrhesía y otras que no saben hacerlo (Foucault, 2009:59).

Los parrhesiastas, son las personas que llevan a cabo el escrache -como actor colectivo-. Serían quienes utilizan la parrbesía, los hombres verídicos, esto es, quienes tienen el coraje de

22 Ley de Punto Final.

23 Ley de Obediencia Debida. 
arriesgar decir veraz, y que arriesgan ese decir veraz en un pacto consigo mismos, en su carácter, justamente de enunciadores de la verdad. Este actor colectivo, la agrupación HIJOS y las agrupaciones de arte activista que los acompañaron y todos los que estuvieron en los escraches, es el -dicho por Foucault"verídico".

Luego de la desaparición de Jorge Julio López ${ }^{24}$, el escrache como acontecimiento verídico o parrhesiático, adquiere más que nunca esta característica que menciona Foucault en el sentido de que "los parrhesiástas son aquellos que, en última instancia, aceptan morir por haber dicho la verdad. O, más exactamente, son aquellos que se proponen decir la verdad a un precio no determinado, que puede llegar hasta su propia muerte [...] ahí está, me parece, el nudo de la parrhesía”. (Foucault, 2009:75)

El parrhesiásta será quien diga la verdad y por consiguiente, se diferencie de todo lo que pueda ser mentira y adulación: "es una manera de decir la verdad".

Cabe decir que los "escrachadores" podrían ser asimilados a los "parrhesiastas" de los que habla Foucault. Son quienes dicen la verdad. Claramente la necesidad de HIJOS era, en ese entonces, denunciar la impunidad institucional: la votación del Poder Legislativo de las leyes de Obediencia Debida y Punto Final y los decretos presidenciales del indulto. En ese sentido, el escrache contribuyó a la revitalización de la lucha por los derechos humanos en aquella adversa situación, al evidenciar públicamente la impunidad de los genocidas y apuntar a generar condena social ante la ausencia de cualquier atisbo de condena legal. HIJOS necesitaba "hablar franco", "decir verdad".

\footnotetext{
24 Jorge Julio López es un albañil y ex militante de una unidad básica peronista barrial, y desde 1985 afiliado al Partido Socialista de La Plata. Desapareció en octubre de 1976 hasta junio de 1979 durante la última dictadura argentina. Por segunda vez, desapareció el 18 de septiembre de 2006, el día en que se realizaron los alegatos de la querella en la Causa que como víctima fuera testigo (durante la presidencia de Néstor Kirchner habiéndose derogado las leyes de Obediencia Debida y Punto Final). Hasta la fecha, Jorge Julio López se encuentra desaparecido.
} 
Partiendo del concepto que hemos elegido, parrhesía, las maneras de decir verdad se analizan o bien por la estructura misma del discurso o bien por la finalidad de éste, o bien, si se quiere por los efectos que esa finalidad acarrea sobre la estructura y con ellos los discursos se analizan según su estrategia. Las diferentes maneras de decir la verdad pueden aparecer como tantas otras formas, sea de una estrategia de la demostración, sea de una estrategia de la persuasión, sea de una estrategia de la enseñanza, sea, por fin de una estrategia de la discusión. ¿Forma parte la parrhesía de una de esas de estrategias (Foucault, 2009:70)

Luego prosigue "la parrhesía no participa de una estrategia de demostración, no es una manera de demostrar [...] aunque puede en efecto utilizar elementos de la demostración [...] Pero no la definirán ni la demostración ni la estructura racional del discurso." (Foucault, 2009:70,71)

Retomando el análisis, el escrache no es solamente una estrategia de demostración, de hecho utiliza elementos de demostración, pero el objetivo es gritar, decir verdad.

Cuando Foucault analiza si la parrbesía es una estrategia de la persuasión o si forma parte del arte de la retórica, si bien ambas se suelen aproximar, interferir y entrelazar, la diferencia para definirla como elemento que no participa de la retórica, es que

la parrhesía se define fundamental, esencial y primordialmente como el decir veraz, mientras que la retórica es una manera, un arte o una técnica de disponer los elementos del discurso con el fin de persuadir. Pero que ese discurso diga o no la verdad no es esencial para la retórica. No hay una forma retórica específica de la parrhesía. Y, en especial, su finalidad no consiste tanto en persuadir, no se trata forzosamente de persuadir. (Foucault, 2009:71)

El primer objetivo que tuvo el escrache fue dar a conocer cuáles eran los rostros de los genocidas, dejarlos expuestos 
públicamente frente a sus vecinos, ya que si bien habían tenido una participación directa en la dictadura, no eran conocidos por toda la sociedad. Los "escrachadores" no tenían necesidad de persuadir, sólo gritar la verdad. Por el contrario, los que recurrían a la retórica y al arte de la persuasión eran los representantes del gobierno que buscaban legitimar sus decisiones políticas utilizando justificaciones como "reconciliación nacional”, "paz social”, cerrando las venas abiertas a través de las leyes de impunidad.

El escrache, tampoco tiene como finalidad o estrategia enseñar, sino como bien dice Foucault cuando habla del parrhesiasta, el escrachador sólo arroja la verdad sobre la cabeza de aquel con el cual dialoga.

No es pedagogía, porque en la parrhesía (al contrario de ella) quien dice la verdad la arroja a la cara de su interlocutor, una verdad tan violenta, tan abrupta, dicha de una manera tan tajante y definitiva que el otro no puede más que callarse, sofocarse de furia. Y es en ese sentido que los genocidas se enfurecían, revestían sus casas de un líquido que no permitía manchar la pared para que las pintadas de los "escrachadores", luego del escrache, se pudieran borrar.

En los escraches no se busca discutir. No hay nada que discutir, justamente, porque la verdad resulta palmaria, y eso es lo que evidencian los "escrachadores": poner el cuerpo y la vida por "decir verdad".

Como ya dijimos, había un riesgo que en el escrache y en los actores sociales que llevaban a cabo acciones de protesta contra el silencio y la invisibilización de la verdad se presentaba en cada momento, en cada acción: con amenazas, intimidación, judicialización de la protesta social con consecuencias penales para los propios parrhesiastas.

Foucault en su clase propone el término más amplio, "vericidad", en vez de "hablar franco", para definir la parrhesía:

La parrhesía es pues cierta manera de hablar. Más precisamente es una manera de decir la verdad. Es [...] una 
manera de decir la verdad, de tal modo que, por el hecho mismo de decirla abrimos, nos exponemos a un riesgo [...] es una manera de abrir ese riesgo ligado al decir veraz al constituirnos en cierta forma como interlocutores de nosotros mismos cuando hablamos, al ligarnos al enunciado y la enunciación de la verdad. Para terminar, la parrhesía es una manera de ligarnos a nosotros mismos en la forma de un acto valeroso. Es el libre coraje por el cual uno se liga a sí mismo en el acto de decir la verdad. E incluso es la ética del decir veraz, en su acto arriesgado y libre. En esa medida, para esa palabra que, en su uso limitado a la dirección de conciencia, se traducía como "hablar franco", creo que podemos, si se (le) da esta definición un poco amplia y general, proponer [como traducción] "el término vericidad" ( 2009:82).

El parrhesiasta, quien utiliza la parrhesía, es el hombre verídico, esto es, quien tiene el coraje de arriesgar el decir veraz, y que arriesga ese decir veraz en un pacto consigo mismo, en su carácter justamente, de enunciado de la verdad. Es "el verídico".

$\mathrm{Al}$ analizar el escrache como acción "verídica" y los "escrachadores" como los "verídicos" es importante destacar lo que dice el autor Pablo Bonaldi, cuando menciona que lo nuevo del escrache es que, en un sentido, desinstitucionaliza el reclamo. Cambia la forma de protesta y el interlocutor al que va dirigida. Ya no es un reclamo o una acción dirigida directamente al gobierno de turno, ni a ninguno de los poderes (legislativo o judicial). HIJOS prescinde de la dimensión estatal para colocar el debate en el seno de la sociedad misma; en ese sentido, el espacio físico elegido como escenario constituye un dato revelador pues las movilizaciones no se realizan hacia la Plaza de Mayo, hacia la sede del poderlLegislativo o del poder judicial, como es habitual en otro tipo de manifestaciones, sino hacia los domicilios de los responsables de los crímenes (Bonaldi, 2006:18). A los fines de nuestro trabajo esto resulta primordial: el objetivo de HIJOS es "escupir" propiamente la verdad en la cara del torturador y por eso van hacia su mismísimo domicilio. 
Foucault, al reparar en la parrhesía como acto verídico en cuatro ejes, va a plantearse que se pone en juego una cuestión filosófica fundamental: el lazo que se establece entre la libertad y la verdad-

¿Cómo y en qué medida la obligación de verdad - "el obligarse a la verdad", "el obligarse por la verdad y el decir veraz" - es al mismo tiempo el ejercicio de la libertad y un ejercicio peligroso de la libertad? ¿En qué sentido (el hecho de) obligarse a la verdad (obligarse a decir verdad, obligarse por la verdad, por el contenido de lo que se dice y por el hecho de decirlo) es efectivamente el ejercicio, y el ejercicio más alto de la libertad? (2009:83)

El hecho de tener su foto, movilizarse a su casa o conocer sus rutinas generaba una sensación de estar muy cerca del genocida. De hecho, los escraches tuvieron mucho de enfrentamiento "cara a cara". En ese sentido, si bien el interlocutor principal al que se dirigían los manifestantes eran los vecinos, a quienes les decían escupían la verdad y les pedían que se sumen al repudio, los HIJOS interpelaban directamente al genocida para enrostrarle sus crímenes pasados y en ese sentido se definía la parrbesía.

\section{Conclusión}

Los escraches como nueva forma de protesta social, como nuevo repertorio de acción colectiva, ya se encuentran instalados dentro de la cultura de acción colectiva de nuestra sociedad.

La misma palabra "escrache", denota la identificación de esa palabra (más allá de su significado en años pasados) con el escrache "inventado" por la Agrupación HIJOS basta sólo buscarla en internet para que el buscador remita a las páginas que explican o narran las historias de esta nueva forma de protesta social. En este sentido seguimos al escritor y periodista Roberto Arlt, porque entendemos que no resulta casual la elección de esa palabra proveniente del lunfardo. Lenguaje precisamente 
nacido del pueblo, de origen rioplatense, que usa palabras que justamente expresan nuevas ideas, cambios, nuevas formas, de cómo irrumpir en el escenario público en las calles, con expresiones artísticas para "escupir" la verdad.

Resaltamos que los escraches consiguieron profundizar y explotar mucho más la lucha por los derechos humanos, siendo una de las acciones de protesta y resistencia que en Argentina llevaron a anular las "leyes de impunidad" y con ello al proceso de reapertura y apertura de causas penales contra los genocidas. La Agrupación HIJOS como nuevo actor social, junto a otros, captaron la activa participación de diferentes grupos, y sobre todo de jóvenes, en una época signada por el descreimiento y la apatía.

Es uno de los procesos de lucha que, profundiza y le da contenido al Derecho Humano fundamental a la verdad. Dentro de ese marco, los "escrachadores", "parrhesiastas", "verídicos" no siguieron las líneas apuntadas desde el poder, como así ningún instinto de compasión ni de autosacrificio, sino por el contrario por el camino de la acción colectiva, pretendieron expresar y "escupir" su verdad, y "poner el cuerpo", líneas de acción que atacaban una supuesta "tranquilidad de vecinos", señalizando con una mancha roja como símbolo, con daños a la "pretendida propiedad privada como valor" que el Estado protegía, desenmascarando a las instituciones democráticas y sus agentes.

El escrache como nueva forma de protesta social, de proceso de lucha, más allá del contexto que le dio origen, se encuentra ya como repertorio de esa acción colectiva, como acto de decir veraz, como acto parrhesiastico de nuestro repertorio cultural. Como parte de nuestra democracia. En este marco, los procesos de luchas colectivas repetidas, son los que le dan el alcance y el verdadero contenido a las instituciones democráticas, profundizando los cambios y transformaciones. Para ello se toma a la democracia no sólo en términos del funcionamiento formal del sistema político, sino como una práctica conflictiva vinculada 
al poder, que refleja las luchas acerca de quiénes podrán decir que en el proceso de definir cuáles son los problemas sociales comunes y cómo serán abordados. Que ello evidencia que el reconocimiento (o negación) de ciertos derechos (individuales y colectivos) a ciertos sujetos (individuales y colectivos); así como la relación Estado-ciudadano, resulta de un proceso histórico -político en continua reestructuración.

\section{Bibliografía}

Antonelli, Mirta Alejandra (2009) "El umbral de reconocimiento del escrache de HIJOS en la dramaturgia societal Argentina". Ponencia presentada en el Primer Congreso Nacional "Protesta Social, Acción Colectiva y Movimientos sociales”. 20-31 de marzo de 2009, Universidad de Buenos Aires.

Arlt, Roberto, (2010 "El idioma de los argentinos", en Aguafuertes porteñas, Losada, Buenos Aires.

Auyero, Javier (2002) "La protesta. Retratos de la beligerancia popular en la Argentina democrática”. Libros del Rojas, Universidad de Buenos Aires, Buenos Aires.

Bonaldi, Pablo (2006) "Si no hay justicia hay escrache. El repudio moral como forma de protesta”, en Apuntes de investigación, $\mathrm{n}^{\circ}$ 11, pp 9-30.

Calveiro, Pilar (2005) Política y/o violencia. Una aproximación a la guerrilla de los años 70. Grupo Editorial Norma. Buenos Aires.

Dictionnaires Le Robert (2006).

Fallos de la Corte Suprema de Justicia (1998) "Urteaga, Facundo R.C. Estado Nacional" (Estado Mayor Conjunto de las FFAA s/ Amparo, Corte Suprema de Justicia de la Nacional 15/10/98).

Foucault, Michel (1979) "Microfísica del Poder". Editorial Piqueta, Madrid.

Foucault, Michel (2009) "El gobierno de si y de los otros", Fondo de Cultura Económica de Argentina, Buenos Aires.

Gobello, José y Stilman, Eduardo (1964), Diálogos de Villoldo, Freeland. Buenos Aires. 
GAC (2009) GAC. "Pensamientos, prácticas, acciones". Ed. Tinta Limon. Buenos Aires.

Herrera Flores, Joaquín (2000) "Hacia una visión compleja de los derechos humanos" en J- Herrera Flores (ed.), El vuelo de Ateneo. Derechos humanos y Critica de la Razón Liberal, Descleé de Brouwer, Bilbaro, pp 19-78.

Longoni, Ana y Bruzzone, Gustavo (comp.) (2008) "El Siluetazo". Adriana Hidalgo editora, Buenos Aires.

Medici, Alejandro y Herrera Flores, Joaquín (2004) "Los derechos humanos y el orden global. Tres desafíos teórico-prácticos.” en Sanchez Rubio, David, Solórzano Alfaro, Norman, Lucena Cid, Isabel V. (Eds.) Los Nuevos colonialismos del capital. Propiedad intelectual, biodiversidad y derechos de los pueblos, Icaria, Barcelona, pp. 97-189.

Nietzsche, Federico (1992) Genealogía de la Moral,. Madrid, Alianza.

Raffin, Marcelo (2006) La experiencia del horror,. Editores del Puerto, Bs. As.

Schuster, F. (2005). "Las protestas sociales y el estudio de la acción colectiva", en Naishtat, F. y Schuster, F. Tomar la palabra. Estudios sobre protesta social y acción colectiva en la Argentina contemporánea, Prometeo, Buenos Aires.

Svampa, Maristella (2005) "La Sociedad Excluyente. La Argentina bajo el signo del neoliberalismo", Aguilar, Altea, Taurus/ Alfaguara, Buenos Aires.

Terruggi, Mario (1974). Panorama del Lunfardo, Cabangon, Buenos Aires.

Verbitsky, Horacio (2011). "Entre Olvido y memoria", en Gabriele Abdreozzi (coord.), Juicios por crímenes de lesa bumanidad en Argentina, Atuel-Cara o Ceca, Buenos Aires. 